\title{
Profile: Interpersonal Communication Skills for Future Coaches
}

\author{
Eko Purnomo ${ }^{1,2, *}$, Amung Ma'mun'1, Nurlan Kusmaedi', Yudy Hendrayana' ${ }^{1}$, Yusuf Hidayat ${ }^{1}$, \\ Nina Jermaina ${ }^{1}$, Eddy Marheni ${ }^{2}$

\begin{abstract}
${ }^{1}$ Doctoral Program of Sports Education, School Postgraduates Studies, Universitas Pendidikan Indonesia, Bandung, 40154, West Java, Indonesia

${ }^{2}$ Faculty of Sports Science, Universitas Negeri Padang, Padang, 25132, West Sumatra, Indonesia
\end{abstract}

Received June 14, 2021; Revised July 20, 2021; Accepted August 22, 2021

\section{Cite This Paper in the following Citation Styles}

(a): [1] Eko Purnomo, Amung Ma'mun, Nurlan Kusmaedi, Yudy Hendrayana, Yusuf Hidayat, Nina Jermaina, Eddy Marheni , "Profile: Interpersonal Communication Skills for Future Coaches," International Journal of Human Movement and Sports Sciences, Vol. 9, No. 5, pp. 964 - 972, 2021. DOI: 10.13189/saj.2021.090518.

(b): Eko Purnomo, Amung Ma'mun, Nurlan Kusmaedi, Yudy Hendrayana, Yusuf Hidayat, Nina Jermaina, Eddy Marheni (2021). Profile: Interpersonal Communication Skills for Future Coaches. International Journal of Human Movement and Sports Sciences, 9(5), 964 - 972. DOI: 10.13189/saj.2021.090518.

Copyright $\odot 2021$ by authors, all rights reserved. Authors agree that this article remains permanently open access under the terms of the Creative Commons Attribution License 4.0 International License

\begin{abstract}
Interpersonal communication is the key to success in communication between coaches and athletes to understand and know the state of an athlete. The purpose of the study was to determine the interpersonal communication skills possessed by prospective trainers. The research method used a descriptive method with survey techniques related to the interpersonal communication skills of prospective trainers. The number of samples in this study was 105 samples with a sampling technique using purposive samples. The sample used in this study is a prospective trainer who has currently completed the basic material and is in the process of completing the advanced material. The results of this study obtained data: 1) Session 1: Sending clear messages, getting a score of $60 \%$ (Need more consistent attention); 2) Session 2: Listening Ability scored 56.19\% (Need more consistent attention); 3) Session 3: Giving and Getting Feedback scored 60\% (Need more consistent attention), 4) Session 4: Handling Emotional Interactions scored 60\% (Need more consistent attention). These results are considered still not high enough, considering that prospective coaches will meet and deal with athletes who have very different characteristics. So, it is hoped that the prospective trainer can improve interpersonal communication skills (not only the ability to train). In this study, it is still limited to find out and collect data on the interpersonal communication skills of prospective trainers. Interpersonal communication improvement programs will
\end{abstract}

be very possible for future research.

Keywords Interpersonal Communication, Life Skills, Future Coach

\section{Introduction}

Currently, knowledge of the physical and cognitive aspects is essential in sports [1]. So, it is not uncommon for sports to be associated with social issues or more complex ones. In addition to knowledge, techniques, strategies, or sports skills, coaches should also know how to teach these skills to players (with communication skills) [2]. Including when talking about team and individual sports, one of the most positive things and a major supporting factor in success is creating a solid team and producing exemplary achievements, one of which is the communication factor [3], [4]. Interpersonal communication is considered a complex social process in both psychology and pedagogy. Communication generally requires more in-depth studies, especially related to mental health data [5]. Understanding its origins, communication is a complex process in which interpersonal factors impact the meaning that everyone connects the messages given and received [6].

Interpersonal skills are indispensable for sports 
activities in the era of globalization [7]. The experience of players/athletes is often influenced by their coaches' interpersonal communication style [8]. Many studies have explained the importance of communication in sports; factors that often appear in team sports are the occurrence of problems between team players [9].

High-level interpersonal skills are essential in all areas of work, including mental health, where interpersonal relationships are an integral and most important source of a process [10]. Regarding interpersonal relationships, coaches hold themselves responsible for athlete development and emphasize the importance of co-workers in building positive sports relationships [11].

In gender differences, interpersonal communication is equally beneficial and equally important [12], including importance in sports [13]. In team sports, the style of interpersonal communication is also very influential on the coach's motivation and commitment to his players [14] or in other words; man will always communicate with other human beings because superior leadership is reflected ineffective communication [15]. Adequate knowledge of field-related techniques and skills is a must, but it is not enough to survive in this era. Communication skills play an essential role in professional life and must be possessed before entering the professional world [16].

Other studies establish that communication is an essential part of successful training practices. Also, training relies heavily on communication competencies, the ability to articulate instructions and procedures clearly, persuasively, and consistently both verbally and nonverbally [17]. Non-verbal communication for a coach becomes an important variable in predicting participants' positive emotional response, satisfaction, and intention of participating in compliance behavior [18].

Also, a coach must have good communication skills to reduce aggressive actions that can be done at any time by the players/athletes. However, the coach's communication skills will be more effective in individual sports, and a lower level of athlete education provides the development of better communication between athletes and coaches [19], [20].

In sports, interpersonal communication's needs and importance are also widely used based on team sports. It was found that team sports showed specific communication patterns, usually displaying a more meaningful message than individual sports types. That team communication was related to more objective performance assessments [9]. Worry or fear associated with speaking in front of others is a problem in communicating and interacting with others [21].

The development of interpersonal communication skills is an essential aspect in developing psychological skills in interactive sports athletes [22]. Athlete sports experience is often influenced by the interpersonal communication style used by coaches [8].

Coaches discuss the importance of working with athlete support networks because they feel athletes receive information and advice from various sources (e.g., parents, other interested parties, other coaches) and can become overwhelmed by the excess of advice and information [23]. Communication in sports emphasizes the characteristics of each sport [24]. Interpersonal conflict is a common problem in athletes, making ineffectiveness and a significant problem in interpersonal communication. [25]. Currently, interpersonal development in young people in sports activities becomes very important and must be done [26] to provide for the child's future. A prospective coach must have interpersonal skills as one of the main assets when becoming a coach later.

\section{Materials and Methods}

\subsection{Research Design}

The research method uses a descriptive method with survey techniques related to the interpersonal communication skills of future trainers. The population used is prospective trainers who are currently studying at the Department of Sports Coaching. The sample in this study amounted to 105 people, taken using a purposive sample technique. The 105 samples are prospective trainers who have completed the basic material and are undergoing advanced material.

\subsection{Procedure}

This research uses descriptive method design with survey technique. In the process of this research, the researcher asked the willingness of each participant to be able to participate in this study. Full protection will be provided by the researcher to the participants (such as: confidentiality of data and other important information). In addition, participants may withdraw at any time in the study if they wish.

First, the researcher conducted a sample search through a local database with the keywords "prospective trainers with advanced material". Because the education process for prospective trainers is carried out using 3 levels (basic, advanced, specialization). Candidates with advanced level are chosen on the grounds that they have at least completed the basic level and have had several experiences as a coach.

After obtaining the number of participants who will be used in this study, the study began by asking the consent of all participants to be used in this study. Furthermore, participants will be given the Interpersonal Communication Competency Scale (ICCS) research instrument. Consists of 10 dimensions: self-disclosure, empathy, social relaxation, assertiveness, interaction management, alter centrism, expressiveness, support, closeness, and environmental control. Each participant is 
required to complete 30 question items related to interpersonal communication skills.

Data collection was carried out in a closed room with a room temperature of $25-27^{\circ} \mathrm{C}$. This is done to provide convenience in the data collection process. The data collection process is carried out only once with a given time (maximum) of 30 minutes.

\subsection{Instrument}

The measure chosen for this study is the Interpersonal Communication Competency Scale [12], [27]-[30]. It was chosen because it is the most comprehensive measure of interpersonal communication competence and provides a better operationalization of the global construct. Competence consists of 10 dimensions: self-disclosure, empathy, social relaxation, assertiveness, interaction management, alter centrism, expressiveness, supportiveness, immediacy, and environmental control. This measure was developed in a relational approach to communication competence which is consistent with the theoretical framework of this study. The items for each dimension are selected from an existing scale that measures a particular dimension or from a construction definition. Thirty items, three per competency dimension, were included on the scale. The authors found an overall alpha for the 30 -item scale of 0.86 . The authors also found a positive relationship between ICCS with other aspects of communication competence (cognitive flexibility and communication flexibility) and strong internal consistency. The factor structure analysis by the authors suggests that the scale is assigned to one factor and will be used as a single factor measure for this study.

\subsection{Data Analysis}

The data analysis used in this study is by simple analysis by percentage. This is enough to know how large (quantity) interpersonal communication skills have by future coaches. Furthermore, in data processing, SPSS 24 is also needed to help facilitate calculation, table creation, and diagrams.

\section{Result and Discussion}

\subsection{Result}

The results of this study at least explain 4 abilities in interpersonal communication (Sending clear messages, Listening Ability, Giving and Getting Feedback, Handling Emotional Interactions). And later from the results of these 4 abilities a final conclusion is formed which there are 3 categories in this study. (1) Need improvement; (2) Need more consistent attention; (3) Potential strength.

In general, the results obtained in this study aim to see how much interpersonal communication skills that future coaches. Interpersonal communication skills are a must for a coach. It will undoubtedly affect how the future coach when already a coach in the future. Theory [31] suggests that communication dynamics should be studied in the idea of coordination and interaction, which means not only limited to understanding and theory.

In table 1 and figure 1 , it is reasonable that interpersonal communication with future coach candidates is still in "Need more consistent attention". This result can be said to be enough because there is still a high probability to be upgraded to "potential strength". However, a slightly concerning factor is that the acquisition of "potential strength" still gets bad results compared to "need improvement".

In table 2 it is stated that all questions given to prospective trainers regarding interpersonal communication all obtained "valid" information using r-table 0.1599. From the calculation of validity, the questions presented meet the requirements and can be assessed very objectively. In addition, the results of the validity test above also show a measure that indicates that the variable being measured is really the variable to be studied by the researcher.

Table 1. Results of Interpersonal Ability Assessment for Future Trainer Candidates

\begin{tabular}{ccccc}
\hline Criteria & Session 1 & Session 2 & Session 3 & Session 4 \\
\hline Need improvement & $26.67 \%$ & $40.00 \%$ & $20.95 \%$ & $30.48 \%$ \\
Need more consistent attention & $60.00 \%$ & $56.19 \%$ & $60.00 \%$ & $46.67 \%$ \\
Potential strength & $13.33 \%$ & $3.81 \%$ & $19.05 \%$ & $22.86 \%$ \\
\hline
\end{tabular}

Note:

Session 1: $\quad$ Sending clear messages

Session 2: Listening Ability

Session 3: $\quad$ Giving and Getting Feedback

Session 4: Handling Emotional Interactions 


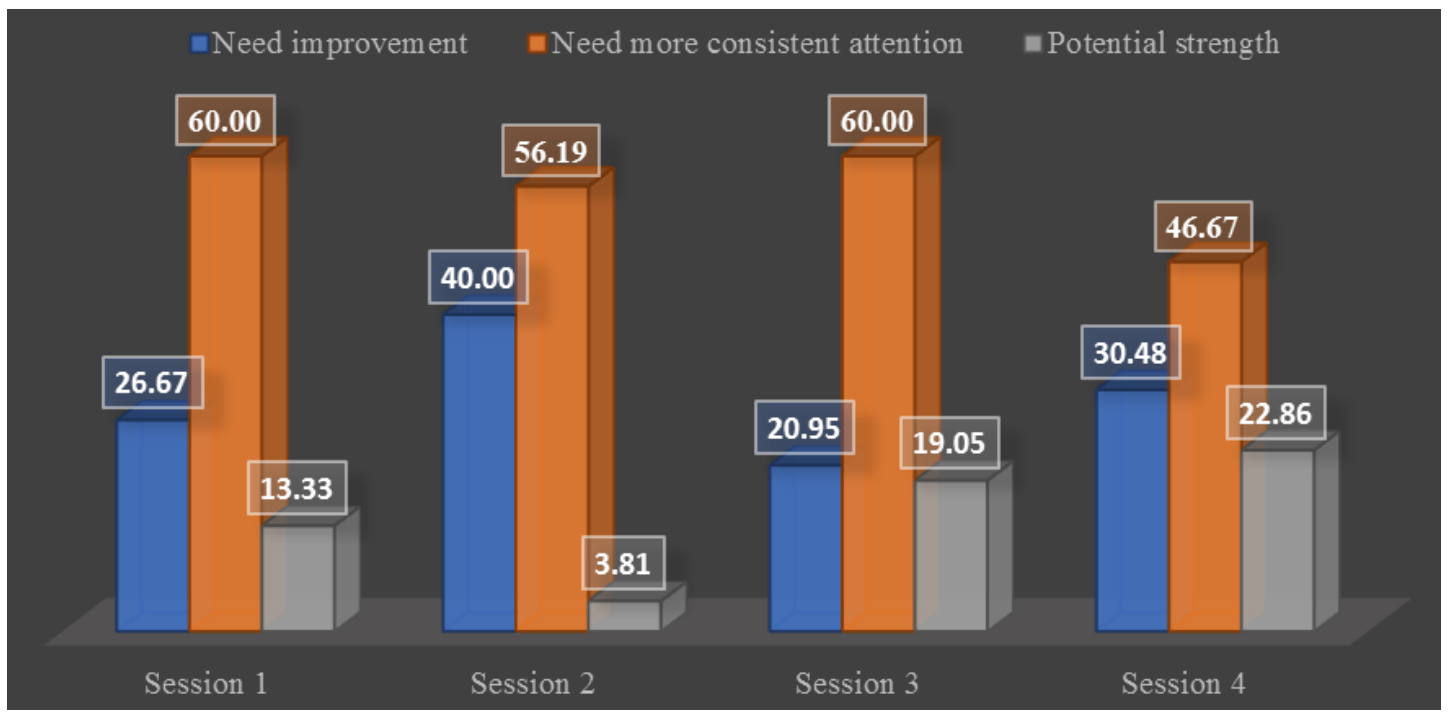

Figure 1. Results Of Interpersonal Ability Assessment For Future Trainer Candidates

Table 2. The results of validation calculation on the acquisition of interpersonal communication of future coaches

\begin{tabular}{|c|c|c|c|c|c|c|}
\hline $\begin{array}{l}\text { Question } \\
\text { Number }\end{array}$ & Session 1 & Session 2 & Session 3 & Session 4 & r-table & Description \\
\hline 1 & 0.5334 & 0.2841 & 0.3722 & 0.3333 & \multirow{10}{*}{0.1599} & valid \\
\hline 2 & 0.3584 & 0.3575 & 0.1675 & 0.6617 & & valid \\
\hline 3 & 0.3366 & 0.2731 & 0.3552 & 0.6686 & & valid \\
\hline 4 & 0.5568 & 0.4109 & 0.4616 & 0.5283 & & valid \\
\hline 5 & 0.2054 & 0.2825 & 0.3015 & 0.5228 & & valid \\
\hline 6 & 0.5580 & 0.1653 & 0.3851 & 0.5022 & & valid \\
\hline 7 & 0.6176 & 0.2616 & 0.3814 & 0.4773 & & valid \\
\hline 8 & 0.2342 & 0.2806 & 0.4168 & 0.2511 & & valid \\
\hline 9 & 0.3847 & 0.4880 & 0.4121 & 0.4860 & & valid \\
\hline 10 & 0.3665 & 0.3477 & 0.4050 & 0.6369 & & valid \\
\hline
\end{tabular}

Table 3. Results of average calculation and standard deviation of interpersonal communication of future coaches

\begin{tabular}{|c|c|c|c|c|c|c|c|c|c|}
\hline \multicolumn{10}{|c|}{ Descriptive Statistics } \\
\hline \multirow{2}{*}{$\begin{array}{l}\text { Question } \\
\text { number }\end{array}$} & \multirow[b]{2}{*}{$\mathbf{N}$} & \multicolumn{2}{|c|}{ Session 1} & \multicolumn{2}{|c|}{ Session 2} & \multicolumn{2}{|c|}{ Session 3} & \multicolumn{2}{|c|}{ Session 4} \\
\hline & & Mean & $\begin{array}{c}\text { Std. } \\
\text { Deviation } \\
\end{array}$ & Mean & $\begin{array}{c}\text { Std. } \\
\text { Deviation } \\
\end{array}$ & Mean & $\begin{array}{c}\text { Std. } \\
\text { Deviation } \\
\end{array}$ & Mean & $\begin{array}{c}\text { Std. } \\
\text { Deviation } \\
\end{array}$ \\
\hline 1 & 105 & 1.75 & 1.072 & 1.20 & 1.041 & 2.22 & 1.065 & 0.58 & 1.026 \\
\hline 2 & 105 & 1.38 & 0.924 & 2.17 & 1.060 & 2.16 & 1.178 & 1.95 & 1.138 \\
\hline 3 & 105 & 1.82 & 1.099 & 1.18 & 1.158 & 1.25 & 1.284 & 1.13 & 1.185 \\
\hline 4 & 105 & 1.26 & 1.135 & 1.35 & 1.065 & 1.45 & 1.263 & 2.07 & 1.031 \\
\hline 5 & 105 & 1.28 & 1.173 & 1.53 & 1.144 & 1.54 & 1.160 & 1.77 & 1.154 \\
\hline 6 & 105 & 1.97 & 1.033 & 2.01 & 1.061 & 1.55 & 1.152 & 1.93 & 1.235 \\
\hline 7 & 105 & 1.96 & 1.100 & 0.84 & 0.878 & 2.41 & 1.007 & 2.73 & 0.724 \\
\hline 8 & 105 & 1.06 & 1.175 & 1.02 & 1.038 & 2.15 & 1.063 & 2.78 & 0.650 \\
\hline 9 & 105 & 1.92 & 1.269 & 2.31 & 1.068 & 1.38 & 1.196 & 1.79 & 1.230 \\
\hline 10 & 105 & 2.60 & 0.839 & 1.50 & 1.218 & 1.81 & 1.186 & 0.82 & 1.116 \\
\hline
\end{tabular}


Standard deviation serves as a measure that can measure the number of variations or spreads of some data values. The lower the normal deviation value, the closer the average, whereas if the standard value deviation, the higher the range of data variations. So, the standard deviation is a big difference from the sample value to the average. In table 3 , the dominant standard deviation value is mean $>$ std. deviation, which means that the data varies less because the standard deviation is smaller than the mean. However, these results can still be used, and continued in this study.

\section{a Sending clear messages}

Despite the importance of effective communication from future coaches, a value-laden message and goals seem to exist in an essential element that future coach candidates should have. Future coaches should know about behavior conducive to persuasive and effective communication of the desired final state. One of the essential tasks a leader has is to communicate the desired final state [15]. Although communication and intent have been emphasized in the message delivered, but sometimes not well received by the listener/recipient. Therefore, providing a good note will affect the greater likelihood of receiving the information conveyed. From the data presented, interpersonal communication capabilities are still in the "need more consistent attention" that should be in the ability of "potential strength".

It is also explained that a teacher or coach's success in conveying a message to students or teachers is also strongly influenced by the ability to receive well from the recipient (student/athlete) [32]. The success of interactions of 2 or more people in traction is influenced by the delivery of a good message and the ability of the recipient of the message well [32].

Figure 2 is an overview of future coaches' capabilities related to sending a good message. The result still requires more attention to be able to achieve the best ability. Therefore, before a prospective coach becomes a real coach, now is the right time to hone and improve the ability to send a good message.

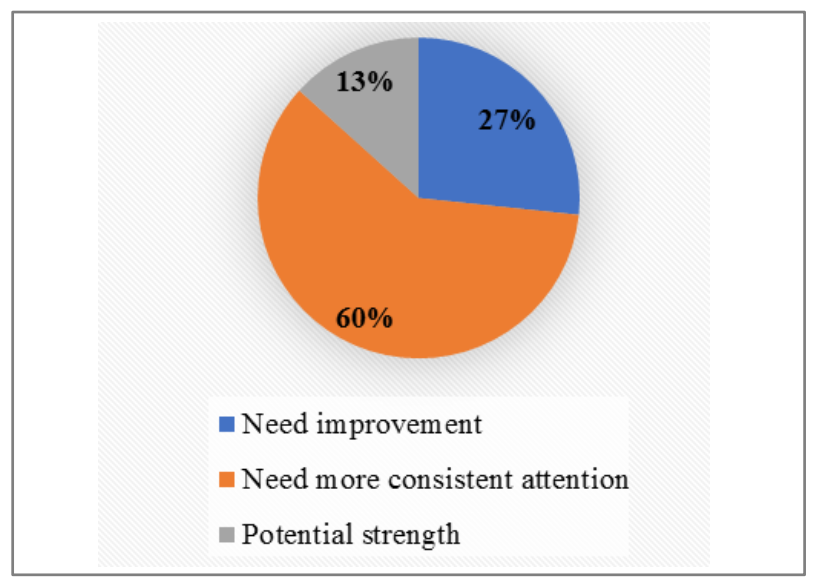

Figure 2. Result of Sending Clear Messages (Session 1)

\section{b Listening Ability}

Although the importance of communication is recognized in several disciplines [31] however, communication-related to the field of sports is still very minimal, so such studies need to continue to be conducted to disseminate the importance of the role of communication in other fields of science, especially in the field of sports. Regardless of the importance of effective communication (vision, value-laden messages, and objectives) [15], future coach candidates must also have the ability to listen to maximize the creation and application of the program as for the formation of the best team.

Listening skills have become a primary concern for researchers and teachers trying to promote communicative competence. The spoken language is more widely used than the written language in life [33], so listening or the ability to understand spoken language is also the most frequently used. A critical opportunity for success shows that two communication skills (listening and speaking) greatly influence interpersonal influence [34]. Approximately three-quarters of the working day is spent conducting a form of communication [35].

Figure 3 provides an overview of the listening abilities of future coaches. The result is also still not as expected; how the product is still far from expected. The ability to listen to future coach candidates must be at the best value; it will be necessary for future coach candidates to listen to the athletes' stories or complaints. Also, the ability to listen will make the most of the creation of targets that meet the athletes' criteria and desires.

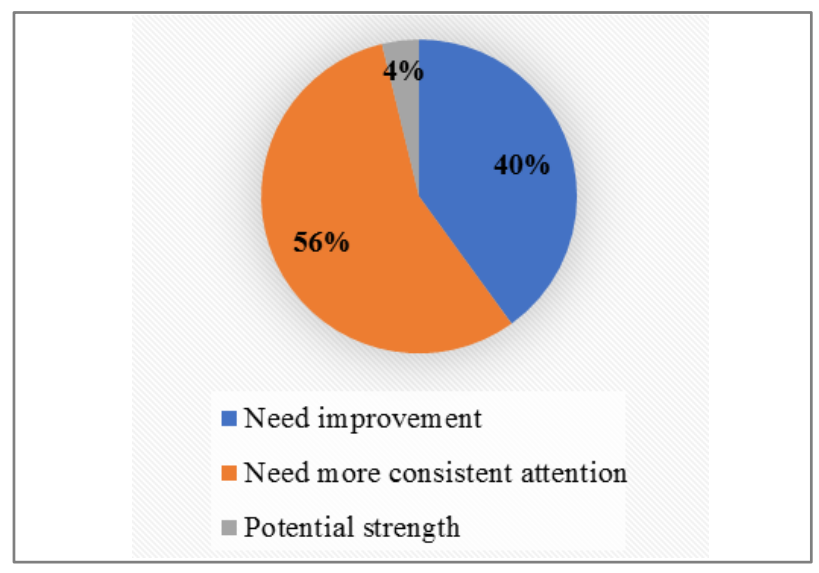

Figure 3. Results of Listening Ability (Session 2)

\section{c Giving and Getting Feedback}

Providing feedback to athletes is a job that a coach must do to make things more conducive. The feedback done by future coaches dramatically impacts the results of the work done. Providing input in communication science is very important in professional activities in various fields or sciences [36].

Feedback can be direct or indirect. This means that 
coaches and athletes can directly provide input (oral) or indirect (through disseminating questionnaires) that athletes can fill because quality feedback communication is the key to success in the assessment process to increase the expected target [36].

The result of the feedback that is used as the basis by a coach in carrying out the future. Feedback is both positive and negative, but it remains to be seen to improve the situation and increase the desired target [37]. Students can recycle good feedback to level up at the moment and reach a higher level.

In figure 4, future coaches' ability related to feedback is still dominated by the acquisition of "need more consistent attention." Still, the positive impact obtained on this result is that "potential strength" experiences a score that almost equals "need improvement"it becomes a better result when compared to "sending clear messages" and "listening ability," which scored $13 \%$ and $4 \%$ respectively.

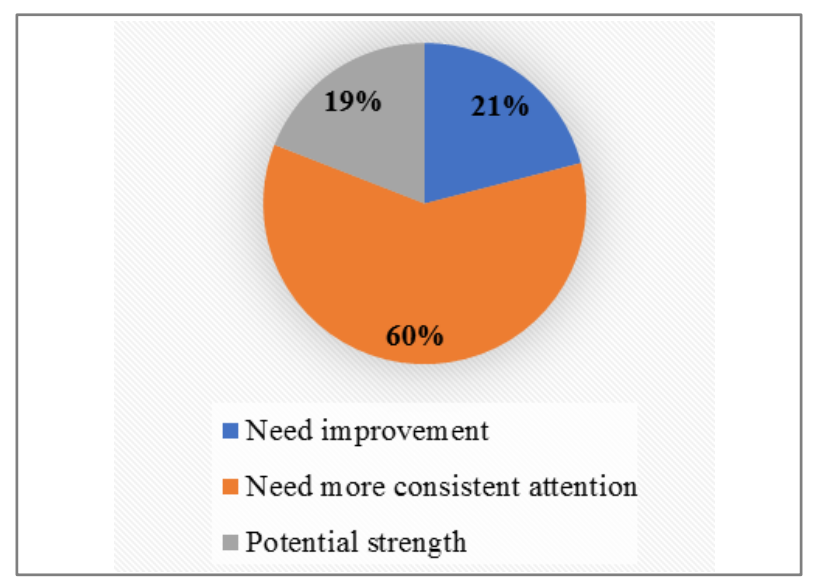

Figure 4. Results of Giving and Getting Feedback (Session 3)

\section{d Handling Emotional Interactions}

Evaluating the level of emotional intelligence is essential for building efficient communication, intellectual and emotional development [38]. These interpersonal skills represent the key to success that contributes to positive interactions and ensures social cohesion. The social function of emotions has provided a compelling evolutionary advantage. Emotions allow individuals to adapt to diverse social demands and opportunities successfully, and the primary function of emotions and their expression is to minimize rejection by other human beings [39].

Suppose these interpersonal skills do not correlate with awareness of reality and socially responsible self-awareness. In that case, there is a risk of social success becoming unable to be achieved to the fullest [38]. Therefore, a future coach needs to understand the emotional interactions that occur within athletes. Thus, with emotions that can be controlled and managed well by the coach, it is possible to deliver the program as expected.

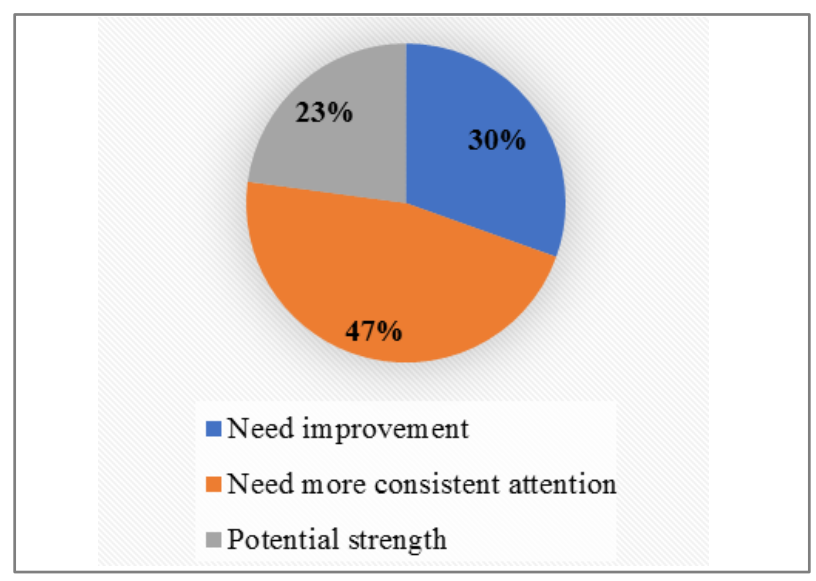

Figure 5. Results of Handling Emotional Interactions (Session 4)

In figure 5 explains the acquisition of test results for future coaches in handling emotional interactions. As a result, future coaches are also still ahead of expected. With the addition of a category dominated by "need more consistent attention" then "need more improvement," and the latter "potential strength" is still an excuse if coaches and athletes even cannot unite in the implementation of training or matches. The result is appropriate or excellent if the coach is in the category of "potential strength".

\subsection{Discussion}

Interpersonal communication is very effective for enhancing cooperation, can be more effective in making members close to each other, and creating a conducive climate [40], [41]. In sports, interpersonal communication is often a major problem for coaches and athletes [25]. Furthermore, the focus of the problem is more specifically on coaching (coach-athlete) [40]-[43]. The interactions that occur can form the people in a team, then the people in the team will make the expected team [41]. Therefore, it is very important to know the interpersonal communication skills in a team in order to form a team that is as expected.

This research is an initial process to create a profile of each individual in a team. By knowing interpersonal communication skills, it is very possible for prospective trainers to be able to improve or even maintain their interpersonal communication skills.

The results of this study explain that from Sessions 1-4, they are still in the medium category (Need more consistent attention). And these results can be used as the basis for future research to improve interpersonal communication skills. Because with abilities that are still in the moderate category, it is possible for prospective coaches to still have trouble or have problems with athletes/players in the future.

In addition, this research is limited to knowing and collecting data on the interpersonal communication skills 
of prospective trainers. Interpersonal communication improvement programs will be very possible for future research.

\section{Conclusions}

Interpersonal communication skills owned by future coaches are still dominant in the category of "need more consistent attention". While the ability of "potential strength" is still not widely owned by future coaches, the worrying thing is that the acquisition of the category "need improvement" is still how much the second category's acquisition of the 2nd category.

The assessed interpersonal communication indicator consists of 4 categories as described earlier. Each class has interrelated functions; communication can't go well if a future coach candidate does not own one component of the existing type. Interpersonal communication is an area as crucial as other fields and also determines success for the future. Interpersonal communication is the key to success in the talk of coaches and athletes to understand and understand each other.

The existence of communication in a sports activity is still not implemented to the maximum. So, research related to sports communication is still not widely carried out. The study's focus is always a favorite is the training program (if implemented in athletes) and learning and curriculum (if implemented in students/schools). It is undoubtedly a task for further research to pay attention to the study or field of communication in sports activities. Considering the study in communication is also as important as other areas of study that can be a determinant of success in implementing sports activities (sports achievement or sports education). Also, the following research that is also no less important that can be carried out by the next researcher is to create a program that can improve interpersonal communication skills for future coaches. Especially programs related to sports activities with an impact on improving communication skills for future coaches.

\section{Acknowledgements}

Thank you to the Postgraduate School, Universitas Pendidikan Indonesia. And also, for the Universitas Negeri Padang. Especially the supervisor, who has supported the completion of this article.

\section{REFERENCES}

[1] J. L. Ubago-Jiménez, G. González-Valero, P. Puertas-Molero, and I. García-Martínez, "Development of emotional intelligence through physical activity and sport practice. A systematic review," Behav. Sci. (Basel)., vol. 9 , no. 4, pp. 8-13, 2019, doi: 10.3390/bs9040044.

[2] L. Athanasios, "Communication problems in professional sports: The case of Greece," Corp. Commun., vol. 10, no. 3, pp. 252-256, 2005, doi: 10.1108/13563280510614500.

[3] P. M. Pedersen, P. C. Laucella, K. S. Miloch, and L. W. Fielding, "The juxtaposition of sport and communication: Defining the field of sport communication," Int. J. Sport Manag. Mark., vol. 2, no. 3, pp. 193-207, 2007, doi: 10.1504/IJSMM.2007.012400.

[4] P. Sullivan and D. L. Felt, "The Preliminary Development of the Scale for Effective Communication in Team Sports (SECTS)," J. Appl. Soc. Psychol., vol. 33, no. 8, pp. 16931715, 2003, doi: 10.1111/j.1559-1816.2003.tb01970.x.

[5] A. Eganov, E. Cherepov, L. Romanova, and V. Bykov, "Interpersonal communication of students and mental health data," J. Phys. Educ. Sport, vol. 20, no. 4, pp. 24052408, 2020, doi: 10.7752/jpes.2020.s4328.

[6] P. Reder and S. Duncan, "Understanding communication in child protection networks," Child Abus. Rev., vol. 12, no. 2, pp. 82-100, 2003, doi: 10.1002/car.787.

[7] H. Lukianets and T. Lukianets, "Global communication competence: A framework of intercultural skills development in sport and tourism higher education," Teor. ta Metod. Fiz. Vihov., vol. 20, no. 2, pp. 77-85, 2020, doi: 10.17309/tmfv.2020.2.03.

[8] D. Matosic, N. Ntoumanis, I. D. Boardley, C. Sedikides, B. D. Stewart, and N. Chatzisarantis, "Narcissism and coach interpersonal style: A self-determination theory perspective," Scand. J. Med. Sci. Sport., vol. 27, no. 2, pp. 254-261, 2015, doi: 10.1111/sms.12635.

[9] P. J. Sullivan and S. Short, "Further Operationalization of Intra-Team Communication in Sports: An Updated Version of the Scale of Effective Communication in Team Sports (SECTS-2)," J. Appl. Soc. Psychol., vol. 41, no. 2, pp. 471487, 2011, doi: 10.1111/j.1559-1816.2010.00722.x.

[10] W. Gadecka, K. Piskorz-Ogórek, K. J. Regin, and I. M. Kowalski, "Social competence of mental health nurses," Polish Ann. Med., vol. 22, no. 2, pp. 105-109, 2015, doi: 10.1016/j.poamed.2015.03.014.

[11] C. Collet, A. V. B. Tozetto, T. Iha, J. V. do Nascimento, W. R. Falcão, and M. Milistetd, "Dynamic elements of sports development: Perceptions of basketball coaches," Rev. Psicol. del Deport., vol. 28, no. 3, pp. 79-85, 2019.

[12] L. R. Diaconu-Gherasim and D. S. Duca, "ParentAdolescent Attachment and Interpersonal Relationships in Sports Teams: Exploring the Gender Differences," Gender Issues, vol. 35, no. 1, pp. 21-37, 2018, doi: 10.1007/s12147-017-9190-0.

[13] A. P. Friesen, A. M. Lane, T. J. Devonport, C. N. Sellars, D. N. Stanley, and C. J. Beedie, "Emotion in sport: Considering interpersonal regulation strategies," Int. Rev. Sport Exerc. Psychol., vol. 6, no. 1, pp. 139-154, 2013, doi: 10.1080/1750984X.2012.742921.

[14] M. Murillo, J. Sevil, Á. Abós, J. Samper, and A. A.-S. y L. G.- González, "Analysis of The Sport Commitment of Young Waterpolists: A Study Grounded in Self-Determination Theory," Rev. Iberoam. Psicol. del 
Ejerc. y el Deport., vol. 13, no. 1, pp. 1-8, 2018, [Online]. Available: http://dx.doi.org/10.1016/j.cirp.2016.06.001.

[15] M. Venus, D. Stam, and D. van Knippenberg, "Leader emotion as a catalyst of effective leader communication of visions, value-laden messages, and goals," Organ. Behav. Hum. Decis. Process., vol. 122, no. 1, pp. 53-68, 2013, doi: 10.1016/j.obhdp.2013.03.009.

[16] E. More and J. Leipzig, "Communication Skills For Professionals," Asia Pacific J. Hum. Resour., pp. 22-25, 1984, doi: 10.1177/103841118402200305.

[17] P. Adigwe and E. Okoro, "Human Communication and Effective Interpersonal Relationships: An Analysis of Client Counseling and Emotional Stability," Int. J. Econ. Manag. Sci., vol. 05, no. 03, pp. 3-6, 2016, doi: $10.4172 / 2162-6359.1000336$

[18] C. H. Bum and K. Lee, "The relationships among non-verbal communication, emotional response, satisfaction, and participation adherence behavior in sports participants," J. Phys. Educ. Sport, vol. 16, no. 2, pp. 1052 1057, 2016, doi: 10.7752/jpes.2016.s2167.

[19] H. Choi, J. A. Park, and Y. Kim, "Decreasing aggression through team communication in collegiate athletes," Sustainability, vol. 11, no. 20, pp. 1-14, 2019, doi: 10.3390/su11205650.

[20] R. Sparks, "Detecting Periods of Significant Increased Communication Levels for Subgroups of Targeted Individuals," Qual. Reliab. Eng. Int., vol. 32, no. 5, pp. 1871-1888, 2016, doi: 10.1002/qre.1919.

[21] B. J. Auer, J. L. Calvi, N. M. Jordan, D. Schrader, and J. Byrd-Craven, "Communication and social interaction anxiety enhance interleukin-1 beta and cortisol reactivity during high-stakes public speaking," Psychoneuroendocrinology, vol. 94, pp. 83-90, 2018, doi: 10.1016/j.psyneuen.2018.05.011.

[22] P. A. Sullivan, "Communication Skills Training for Interactive Sports," Sport Psychol., vol. 7, no. 1, pp. 79-91, 2016, doi: 10.1123/tsp.7.1.79.

[23] D. Gould, J. Nalepa, and M. Mignano, "Coaching Generation Z Athletes," J. Appl. Sport Psychol., vol. 32, no. 1, pp. 104-120, 2020, doi: 10.1080/10413200.2019.15818 56.

[24] Y. Kim and I. Park, “'Coach really knew what i needed and understood me well as a person': Effective communication acts in coach-athlete interactions among Korean olympic archers," Int. J. Environ. Res. Public Health, vol. 17, no. 9, 2020, doi: 10.3390/ijerph17093101.

[25] S. Wachsmuth, S. Jowett, and C. G. Harwood, "Conflict among athletes and their coaches: What is the theory and research so far?," Int. Rev. Sport Exerc. Psychol., vol. 10, no. 1, pp. 84-107, 2017, doi: 10.1080/1750984X.2016.118 4698.

[26] C. Harwood, "Developmental consulting in a professional football academy: The 5Cs coaching efficacy program," Sport Psychol., vol. 22, no. 1, pp. 109-133, 2008, doi: 10.1123/tsp.22.1.109.

[27] J. A. DeVito, The Interpersonal Communication Book 13th Edition, 13th ed. United States of America: Pearson
Education, Inc., 2013.

[28] M. Macik-Frey, "Communication-Centered Approach To Leadership: The Relationship Of Interpersonal Communication Competence To Transformational Leadership And Emotional Intelligence," Univ. Texas Arlingt., no. May, 2007.

[29] G. D. Gottfredson, "Schools and Delinquency," Oxford Handb. Juv. Crime Juv. Justice, no. September 2018, pp. 129, 2011, doi: 10.1093/oxfordhb/9780195385106.013.000 9.

[30] S. V. Hald, F. A. Baker, and H. M. O. Ridder, "A preliminary psychometric evaluation of the interpersonal communication competence scale for aquired brain injury," Brain Inj., vol. 29, no. 9, pp. 1105-1112, 2015, doi: 10.3109/02699052.2015.1024740.

[31] G. Pezzulo, F. Donnarumma, and H. Dindo, "Human sensorimotor communication: A theory of signaling in online social interactions," PLoS One, vol. 8, no. 11, 2013, doi: 10.1371/journal.pone.0079876.

[32] H. Patrick, L. H. Anderman, A. M. Ryan, K. C. Edelin, and C. Midgley, "Teachers' communication of goal orientations in four fifth-grade classrooms," Elem. Sch. J., vol. 102, no. 1, pp. 35-58, 2001, doi: 10.1086/499692.

[33] P. T. Rankin, "The Importance of Listening Ability," English J., vol. 17, no. 8, pp. 623-630, 2015.

[34] R. D. Costigan and K. E. Brink, "Developing Listening and Oral Expression Skills: Pillars of Influential Oral Communication," J. Manag. Educ., vol. 44, no. 2, pp. 129164, 2020, doi: 10.1177/1052562919890895.

[35] P. J. Helms, M.M. and Haynes, “Are you really listening?," Nurs. N. Z., vol. 2, no. 4, pp. 20-21, 1994, doi: $10.4324 / 9781315422497-13$.

[36] S. Y. F. Tang and A. W. K. Chow, "Communicating feedback in teaching practice supervision in a learning-oriented field experience assessment framework," Teach. Teach. Educ., vol. 23, no. 7, pp. 1066-1085, 2007, doi: 10.1016/j.tate.2006.07.013.

[37] V. L. Michelle Brown, Carol T Kulik, "Personnel review," Disabil. Employ., vol. 30, no. 2, pp. 152-169, 2001.

[38] A. Petrovici and T. Dobrescu, "The Role of Emotional Intelligence in Building Interpersonal Communication Skills," Procedia - Soc. Behav. Sci., vol. 116, pp. 14051410, 2014, doi: 10.1016/j.sbspro.2014.01.406.

[39] G. Andersen, "Handbook of Communication and Emotion," Handb. Commun. Emot., pp. 49-96, 1996, [Online]. Available:http://www.sciencedirect.com/science/article/pii /B9780120577705500059.

[40] M. Raut, "Interpersonal communication and contraception: Insights and evidences from Bangladesh demographic and health survey, 2011," Indian J. Public Health, vol. 59, no. 3, p. 220, 2015, doi: 10.4103/0019-557x.164666.

[41] I. Hutagalung, "The Function of Interpersonal Communication in Conflict Management Organization," SHS Web Conf., vol. 33, p. 00009, 2017, doi: $10.1051 /$ shsconf/20173300009. 
[42] R. Nazari, M. Ehsani, F. A. Gangoei, and H. Ghasemi, "The Effects of Communication Skills and Interpersonal Communication on Organizational Effectiveness of Iranian Sport Managers and Presenting a Model," Middle-East J. Sci. Res., vol. 10, no. 6, pp. 702-710, 2011.
[43] Rasool Nazari, "Structural equation modeling of relationship and interpersonal communication on organizational effectiveness between sport managers," African J. Bus. Manag., vol. 6, no. 27, pp. 8136-8145, 2012, doi: 10.5897/ajbm11.2912. 